\title{
First rank symptoms: concepts and diagnostic utility
}

\author{
S Saddichha', R Kumar', S Sur ${ }^{3}$, BNP Sinha \\ 1National Institute of Mental Health \& Neurosciences (NIMHANS), Bangalore, India \\ 2Department of Psychiatry, Central Institute of Psychiatry, India \\ ${ }^{3}$ Ranchi Institute of Neuropsychiatry and Allied Sciences, India \\ 4University Hospital of North Tees, Cleveland, UK
}

\begin{abstract}
First Rank Symptoms (FRS) were first defined by Schneider as diagnostic of schizophrenia. Since then, there has been an immense debate on their diagnostic and prognostic utility. This review attempts to understand the concepts of FRS as depicted over the years and the diagnostic and prognostic implications of FRS in mental illnesses including schizophrenia. Review of relevant material showed that there are wide variations in the concepts of FRS which may be classified according to broad and narrow definitions. These variations have also led to the differences in the diagnostic systems currently being used. Although the diagnostic utility of FRS in schizophrenia remains, it is not clearly so with other mental illnesses in which these symptoms may also be observed. In addition there is controversy over the prognostic implications with evidence divided between poor and no influence on outcome.
\end{abstract}

Key words: First rank symptoms; Schizophrenia; Diagnosis; Prognosis

Received: 01-07-2009

Accepted: $30-07-2009$

\section{Introduction}

Eliciting first rank symptoms (FRS), giving rise to the diagnoses of schizophrenia and related illnesses, forms part of the clinical assessment process. Although the concept of FRS is evolving these symptoms are widely used in several diagnostic criteria for schizophrenia, having initially been proposed by Schneider (1959). ${ }^{1}$ They have been the subject of much debate with a focus on the role they have played in diagnostic systems and on their psychopathological and prognostic importance. Further, the first rank symptoms of Schneider have come under considerable criticism in recent times, especially regarding their reliability and specificity for the diagnosis of schizophrenia. Even if FRS were shown to have acceptable specificity for a diagnosis of schizophrenia, the question remains as to whether they occur with sufficient frequency in a given disorder to be diagnostically useful. ${ }^{2}$ This review, whilst not necessarily comprehensive, attempts to understand the concepts of FRS as described over the years

\section{Correspondence}

Dr S Saddichha

National Institute of Mental Health \& Neurosciences (NIMHANS)

Bangalore, India

email: saddichha@gmail.com as well as the diagnostic and prognostic implications of FRS in mental illnesses including schizophrenia.

\section{Concept of FRS}

It has been suggested that instead of being clear cut symptoms, FRS lie along a continuum which can be arranged as first rank and first rank - like symptoms according to phenomenological principles. ${ }^{3}$ As various authors have defined FRS differently, each FRS could be viewed as a continuum between a narrow and wide definition. Hence using the narrow definition of FRS would produce greater specificity of schizophrenia and a wider definition a greater sensitivity. These definitions have mainly been drawn from Mellor ${ }^{4}$, Hamilton ${ }^{5}$, Wing and colleagues ${ }^{6}$ and Taylor \& Heiser $^{7}$, the narrow definitions in all cases being that of Mellor ${ }^{4}$. The various narrow and wide definitions are given below ${ }^{8}$

(a) Made feelings, made impulses, made action, somatic passivity.

(i) Narrow: the subject experiences these sensations as not being his own but as arising from an outside source.

(ii) Wide: the subject experiences them as his own, but as being controlled from outside. 
(b) Thought insertion

(i) Narrow: the subject experiences thoughts as not being his own and being inserted into his mind

(ii) Wide: the subject experiences them as being controlled from outside.

\section{(c) Thought withdrawal}

(i) Narrow: the thoughts cease in the subject's mind owing to the direct influence of an outside agency.

(ii) Wide: thought block is accepted in the absence of an experience or thoughts being interfered with by an outside agency.

\section{(d) Thought broadcast}

(i) Narrow: the subject not only experiences thoughts leaving the confines of his own mind, but also experiences them being shared with others.

(ii) Wide: either thought leave the confines of the subject's mind but are not shared or they are so loud that others can hear them.

(e) Voices in discussion, voice commentary, audible thoughts

(i) Narrow: The voices are heard outside the subject's head (true hallucination).

(ii) Wide: The voices are heard only inside the subject's head/mind

\section{(f) Delusional perception}

(i) Narrow: the delusional idea and the perception are directly linked to one another such that the delusional idea cannot be separated from the perception and occurs in very close temporal relationship to it.

(ii) Wide: there is a relatively loose link between a perception and a delusional idea and the delusional idea is often linked, with other phenomena.

\section{Comparative nosology}

In ICD-99 , although the terms used were not similar to FRS, the phenomena described were similar and amounted to six FRS being mentioned: thought broadcasting, thought withdrawal, thought insertion, made acts, voices commenting and voices discussing. In ICD-1010, FRS prominently appears in criterion $\mathrm{A}-\mathrm{C}$, and the number increases to eight with somatic passivity and delusional perception appearing in criterion B. In DSM III $^{11}$ and DSM IV TR ${ }^{12}$, there are no symptoms unique to schizophrenia, although it emphasizes the importance of bizarre delusion and FRS (criterion A). However in both DSM editions, the degree to which the FRS delusion and bizarre delusion define different phenomena remains unclear. In the DSM-III-R ${ }^{13}$, a bizarre delusion is defined as "involving a phenomenon that the person's culture would regard as totally implausible, e.g., thought broadcasting and being controlled by a dead person". Both of these examples are arguably similar to FRS, thus creating a certain amount of confusion regarding the extent to which bizarre delusions and FRS delusions can be overlapping concepts. However, in the text accompanying the DSM-IV ${ }^{14}$, bizarre delusions are defined as "clearly implausible, not understandable and not derived from ordinary life experiences."

\section{Diagnostic utility}

First rank symptoms, intended only for pragmatic diagnostic use, take precedence over 2 nd rank symptoms for diagnostic reasons. 2nd rank symptoms and expressive phenomena may often justify the diagnosis of schizophrenia by virtue of their combination and accumulation ${ }^{15}$ but they do not have the same diagnostic power as FRS. The prevalence of FRS in schizophrenia has however differed in various studies and cultural contexts from $25.4 \%$ to $88 \%$ (Table I).

However, FRS have been observed in mental disorders other than schizophrenia, and even in the normal population. Many studies have been conducted to show the prevalence of first rank symptoms in patients other than schizophrenia (Table II). Although the numbers have varied from 1\% to 32\%, the prevalence of FRS in non-schizophrenic patients is significantly less than seen in schizophrenia patients. FRS have been observed in multiple personality disorder (MPD). ${ }^{16-18}$ MPD has been differentiated from eating disorder, panic disorder and complex partial seizures using FRS. ${ }^{18}$ In fact Ross and colleagues ${ }^{18}$ believe that the greater the number of first rank symptoms reported, the more likely is the diagnosis of multiple personality disorder and the less likely that of schizophrenia. Recently, Conus et al ${ }^{19}$ have shown that the presence of first rank symptoms at baseline are significantly associated with earlier onset of psychosis as well as increased severity of negative symptoms and poorer

Table I: Prevalence of FRS in schizophrenia in different studies

\begin{tabular}{|l|l|l|l|}
\hline Investigators & Method & No. Of Pts. & FRS Percentage (\%) \\
\hline Huber, 1967 ${ }^{34}$ & Chart review & 195 & 72 \\
Mellor, 19704 & Interview & 166 & 78.9 \\
Taylor, 1972 22 & Chart review & 34 & 64 \\
Carpenter et al., 197335 & Interview & 103 & 51 \\
Abrams et al., 197436 & Interview & 11 & 54 \\
Carpenter, et al., 1974 (IPSS data)30 & Interview & 811 & 57 \\
Wing et al., 1975 (IPSS data) ${ }^{37}$ & Interview & 810 & 51 \\
Koehler et al, 197738 & Chart & 210 & 33 \\
Bland, 197823 & Chart & 50 & 88 \\
Chandrasena \& Rodrigo, 197939 & Interview & 169 & 25.4 \\
Radhakrishnan et al, 198326 & Interview & 88 & 35 \\
O'Grady, 1990 & Interview & 99 & 73 \\
Tanenberg-Karant et al, 199540 & Interview & 94 & 72 \\
\hline
\end{tabular}




\begin{tabular}{|c|c|c|c|}
\hline Investigators & Method & Diagnosis ( $N=$ Sample size) & FRS present (\%) \\
\hline Taylor, $1972^{22}$ & Chart & $\begin{array}{l}\text { Mania (7) } \\
\text { Depression (8) } \\
\text { Neuroses \& PD(18) }\end{array}$ & $\begin{array}{l}0 \\
0 \\
0\end{array}$ \\
\hline Carpenter et al, $1973^{35}$ & Interview & $\begin{array}{l}\text { Affective. Psychoses (39) } \\
\text { Neuroses(23) }\end{array}$ & $\begin{array}{l}23 \\
9\end{array}$ \\
\hline Abrams et al, $1974^{36}$ & Interview & Mania (43) & 9 \\
\hline Taylor et al, $1973^{41}$ & Interview & Mania (52) & 11.5 \\
\hline Carpenter et al, 1974 (IPSS study) $)^{30}$ & Interview & $\begin{array}{l}\text { Mania (66) } \\
\text { Depression(119) } \\
\text { Neuroses \& Personality Disorders(123) }\end{array}$ & $\begin{array}{l}23 \\
16 \\
12.7\end{array}$ \\
\hline Wing et al, 1975 (IPSS study) 37 & Interview & $\begin{array}{l}\text { Mania (79) } \\
\text { Depression (176) } \\
\text { PD/Neuroses (53) }\end{array}$ & $\begin{array}{l}16 \\
5 \\
7.2\end{array}$ \\
\hline Marsha et al (1995)40 & Interview & Bipolar Affective Disorder (62) & 32 \\
\hline Radhakrishnan et al (1983)26 & Interview & $\begin{array}{l}\text { Affective Disorders (46) } \\
\text { Hysterical Psychosis (39) } \\
\text { Paranoid State (6) } \\
\text { Antipsychotic (9) } \\
\text { TLE(6) }\end{array}$ & $\begin{array}{l}1 \\
7 \\
2 \\
22 \\
3.2\end{array}$ \\
\hline$O^{\prime} \operatorname{Grady}(1990)^{8}$ & Interview & Affective Disorder(34) & 14 \\
\hline
\end{tabular}

psychosocial functioning after 12 months. In addition, 7\% of patients with organic mental disorders have been noted to have first rank symptoms compared with $47 \%$ of schizophrenia patients. ${ }^{20}$ However, Marneros ${ }^{20}$ believes that the frequency of first rank symptoms depends on the state of consciousness and on the etiology of the organic mental disorder. There are a number of neurological illnesses, which are associated with psychiatric presentations in the absence of clouding of consciousness such as head trauma, encephalitis, psychosis associated with Huntington's disorder, multiple sclerosis and various inter-ictal manifestations of epilepsy. ${ }^{21}$

\section{Prognostic and diagnostic implications of FRS}

The prognostic implications of FRS remain equivocal. Some maintain that FRS is associated with poor prognosis ${ }^{22-24}$, while others argue that FRS have no prognostic implications. ${ }^{25-27}$ In non-schizophrenic mental illnesses, the presence of FRS has again been controversial in being associated with outcomes that are both positive ${ }^{19,28}$ and negative..$^{29}$

The diagnostic implications of FRS are however influenced to a large extent by the cross-cultural variation of prevalence of first rank symptoms among schizophrenia patients and patients other than schizophrenia. Carpenter and Strauss ${ }^{30}$ confirmed the wide variability across nine countries showing an overall prevalence of $57 \%$, with findings from London and Taipei reporting highs of $76 \%$ and $79 \%$ respectively, whereas findings Moscow and Washington reported lower rates of $31 \%$ and $20 \%$ of patients respectively.
It has been observed that a higher prevalence of cultural and sub cultural beliefs among ethnic minorities may contribute towards low prevalence but that a true reduction also appears to be present. ${ }^{31}$

Unfortunately, fair comparisons between different prevalence studies of Schneider's first rank symptom are difficult for several reasons. The primary problem appears to be that of definitions used with clinicians and researchers tending to vary from the original definitions used by Schneider. ${ }^{3}$ This may partly be due to Kurt Schneider's original writings being in the German language and the quality of first rank symptoms being lost in the translations. Further, Schneider in his original writings did not define each of the first rank symptoms. The uses of varying clinical definitions therefore contribute to variations in the prevalence. Another difficulty in comparing studies relates to variations in methodology. The Present State Examination (PSE) ${ }^{6}$, which reliably elicits only severe first rank symptoms, was used during the International Pilot Study of Schizophrenia (IPSS)* while Mellor ${ }^{4}$ used strictly defined clinical criteria. Further, the phenomenology of schizophrenic subtypes seems to vary with a higher prevalence of catatonic schizophrenia more prevalent in South East Asia when compared to the West, in the IPSS (India: 44\% vs. UK: 4\%). Other studies have also made similar observations. ${ }^{32,33}$ The diagnostic utility of FRS appears then to be affected by several limitations, as observed above.

*World Health Organization. Report of the International Study of Schizophrenia Vol. 1 WHO, Geneva, 1973 


\section{Conclusion}

Studies of FRS are still important and relevant since FRS are considered to be more objective and easier for clinicians to recognize as opposed to for example the more non-specific negative symptoms. Schneiderian first-rank symptoms are important as a psychopathological construct though their importance in diagnosing schizophrenia has somewhat lessened due to their prevalence in various other conditions. However, according to the current nosology, their presence is a strong indicator for a diagnosis of schizophrenia if other causes can be excluded. Future studies need to look at developing neurobiological models of FRS in order to map and delineate boundaries so as to improve the understanding of the prognostic and diagnostic implications of individual FRS.

\section{References}

1. Schnieder K. Klinische Psychopathologie 12th edition: Stuttgart Georg Thieme Verlag, 1980 as cited in: Crichton, P. (1996). FirstRank symptoms or Rank- and file symptoms? Br J Psychiatry 169; 537-540.

2. Andreasen NC, Akiskal HS. The specificity of Bleulerian and Schneiderian Symptoms: A critical Reevaluation. Psy Clin North America 1983; 6 (1): 41-54

3. Koehler K. First-rank symptoms of schizophrenia: questions concerning clinical boundaries. Br J Psychiatry 1979; 134: 236-248.

4. Mellor CS. First rank symptoms of schizophrenia: The frequency in schizophrenics on admission to hospital. Br J Psychiatry 1970; 117 (536): 15-23.

5. Hamilton M. Fish's Schizophrenia, 3rd ed: Wright PSG, London, 1984.

6. Wing JK, Cooper JE, Sartorius N. Measurment and Classification of Psychiatric Symptoms. An Instruction Manual for the PSE and Catego Progam. Cambridge : Cambridge University Press, 1974.

7. Taylor MA, Heiser JF. Phenomenology: an alternative approach to diagnosis of mental disease. Comp Psychiatry 1971; 12(5):480-486.

8. O'Grady JC. The prevalence and diagnostic significance of Schneiderian first-rank symptoms in random sample of acute psychiatric in-patients. Br J Psychiatry 1990; 156: 496-500.

9. World Health Organization. International Classification of Diseases. 9th edition: WHO Geneva, WHO, 1978.

10. World Health Organization. The ICD-10 International Classification of Mental and Behaviour Disorders. Clinical Description and Diagnostic Guidelines, WHO Geneva, 1992.

11. American Psychiatric Association. Diagnostic and Statistical Manual of Mental Disorders. 3rd edition: Washington DC, APA, 1980.

12. American Psychiatric Association. Diagnostic and Statistical Manual of Mental Disorders. 4th edition, text revision: Washington DC, APA, 2000 .

13. American Psychiatric Association. Diagnostic and Statistical Manual of Mental Disorders. 3rd edition revision: Washington DC, APA, 1987.

14. American Psychiatric Association. Diagnostic and Statistical Manual of Mental Disorders. 4th edition: Washington DC, APA, 1994

15. Schneider K. The concept of delusion. Themes and Variations in European Psychiatry. Charlottesville, VA: University of Virginia Press, 1974.

16. Kluft RP. First-rank symptoms as a diagnostic clue due to multiple personality disorder. Am J Psychiatry 1987; 144: 293-298.

17. Ross CA, Heber S, Anderson G. Differences between multiple personality disorder and other diagnostic groups on structured interview. J Nerv Ment Dis 1989; 177: 487-491.
18. Ross CA, Norton GR. Multiple personality patients with a past diagnosis of schizophrenia. Dissociation 1988; 1: 39-42.

19. Conus P, Abdel-Baki A, Harmigam S. Schneiderian first rank symptoms predict poor outcome within fist episode manic psychosis. J Affective Disord 2004; 81: 259-268.

20. Marneros A. Schizophrenic first rank symptoms in organic mental disorders. Br J Psychiatry 1988; 152: 625-628.

21. Trimble MR. Neuropsychiatry. Chichester: John Wily \& Sons, 1981.

22. Taylor MA. Schneiderian first-rank symptoms and clinical prognostic features in schizophrenia. Arch Gen Psychiatry 1972; 26: 64.

23. Bland RC. Diagnosis of schizophrenia. Can Psych Assoc J 1978; 23. 291-296.

24. Kendell RE, Brockington IF, Leff JP. Prognostic implications of six alternative definitions of schizophrenia. Arch Gen Psychiatry 1979; 36(1): 25-31.

25. Bland RC, Orn H. Schizophrenia: diagnostic criteria and outcome. Br J Psychiatry 1979;134: 34-8

26. Radhakrishnan J, Mathew K, Richard J, Verghese A. Schneider's first rank symptoms: prevalence, diagnostic use and prognostic implications. Br J Psychiatry 1983; 142: 557- 559.

27. Thorup A, Petersen L, Jeppesen P, Nordentoft M. Frequency and predictive values of first rank symptoms at baseline among 362 young adult patients with first-episode schizophrenia- Results from the Danish OPUS study. Schizophrenia Res 2007; 97(1-3): 60-7

28. Tohen M, Tsuang MT, Goodwin DC. Prediction of outcome in mania by mood-congruent or mood-incongruent psychotic features. Am J Psychiatry 1992; 149(11): 1580-4

29. Pi EH, Surawicz FG. Schizo-affective disorder (Schneiderian positive), manic type: a comparison with mania. J Clin Psychiatry 1982;43(6):235-6.

30. Carpenter WT, Strauss JS. Cross cultural evaluation of Schneider's first rank symptoms of schizophrenia: a report from the International Pilot Study of Schizophrenia. Am J Psychiatry 1974; 131: 682-687

31. Chandrasena R. Schneider's first-rank symptoms: An international and interethnic comparative study. Acta Psychiatr Scand 1987; 76: 574-578.

32. Neki J. Psychiatry in south east Asia. Br J Psychiatry 1973; 123: $257-$ 269.

33. Salleh MR. Specificity of Schneider's first rank symptoms for schizophrenia in Malay patients. Psychopathol 1992; 25: 199-203.

34. Huber G. Course of psychiatric disease manifestations and pharmacotherapy. Med Welt. 1967; 24;25:1517-20.

35. Carpenter WT, Strauss JS, Muler S. Are there pathognomonic symptoms in schizophrenia? Arch Gen Psychiatry 1973; 28: 847-852.

36. Abrams R, Taylor MA, Gaztanaga P. Manic depressive illness and paranoid schizophrenia. Arch Gen Psychiatry 1974; 31: 640-642.

37. Wing JK, Nixon J. Discriminating symptoms in schizophrenia. Arch Gen Psychiatry 1975; 32: 853-859.

38. Koehler K, Guth W, Grimm G. First rank symptoms of schizophrenia in Schneider-oriented German Centers. Arch Gen Psychiatry 1977; 34: 810-813.

39. Chandrasena $R$, Rodrigo A. Schneider's first-rank symptoms, their prevalence and diagnosis implication in an Asian population. Br J Psychiatry 1979; 135:348-351.

40. Tanenberg-Karant M, Fenning S, Ram R, Krishna J, Jandorf L, Bromet EJ. Bizarre delusions and first rank symptoms in a first admission sample: A preliminary analysis of prevalence and correlates. Comp Psychiatry 1995; 36 (6): 428-434.

41. Taylor MA, Abrams R. The phenomenology of mania: a new look at some old patients. Arch Gen Psychiatry 1973; 29: 520-522. 